\title{
Bayesian Network Applied to the Analysis of Farmers' Technical Demand
}

\author{
Haiyan Wang ${ }^{1, a}$, Xiwu Shao ${ }^{2, b, *}$ \\ ${ }^{1}$ Higher Education Research Institute, Jilin Agricultural University, Changchun 130118, China \\ ${ }^{2}$ College of Administration, Jilin Agricultural University, Changchun 130118, China \\ a382408886@qq.com; 'xiwushao@126.com
}

Keywords: Bayesian Network; technical demand; individual differences.

\begin{abstract}
The farmer is the main body of agricultural technology demand. The Bayesian Network method was adopted to entropy reduction and sensitivity analysis in this paper, we determined the order of the factors that influenced famers to adopt technology. Through related economic analysis, this paper believed that we must really understood the technical demand of farmers, master farmers' psychological characteristic and behaviors, analyze the problems in the using the technical. At the same time, we should stand on the farmers, carry out planned, this will reduce the risk of farmers to adopt new technology.
\end{abstract}

\section{Introduction}

Bayesian network originated in the mid-1980s to study of the artificial intelligence system uncertainty problem, it is an effective tool for complex system uncertainty reasoning and data analysis.

Bayesian network is a two tuple $S=<G, P>$, among them: $\mathrm{G}$ is a finite acyclic graph, graph of random variable node and domain knowledge in the network corresponds to one, represent causal relationship between variables to arc, arc to the intuitive meaning is that the $\mathrm{X}$ has a direct causal influence on $\mathrm{Y}$ from node $\mathrm{x}$ to node $\mathrm{y} ; \mathrm{P}$ is a collection of local probability distribution, $P=P\left\{P\left(x \mid \pi_{x}\right)\right\}$ the conditional probability that the causal impact strength, which $\pi_{x}$ the father node represents a node set X [1]. After the Bayesian network construction, we can reduce the amount and the sensitivity analysis by means of entropy, to determine influence technology adoption (accept) the order of the factors.

The entropy $\mathrm{H}(\mathrm{X})$ of a discrete random variable $\mathrm{X}$ is defined as:

$$
H(X)=\sum_{x} P(X) \log \frac{1}{P(X)}=-\sum_{x} P(X) \log P(X)
$$

Log in on type 2 to the end, then the entropy is bit; if e, then the unit is the knight. This paper takes the bit as a unit, that is, to the base 2 .

When $\mathrm{Y}$ is given $\mathrm{X}$ 's definition of conditional entropy as followed:

$$
H(X \mid Y)=-\sum_{Y} P(Y) \sum_{X} P(X \mid Y) \log P(X \mid Y)
$$

Obviously, in the previously observed $Y$, the uncertainties of the $\mathrm{X}$ is $\mathrm{H}(\mathrm{X})$. Through the observation of $\mathrm{Y}$, the uncertainties of the $\mathrm{X}$ into $\mathrm{H}(\mathrm{X} \mid \mathrm{Y})$. Reduce the amount of information entropy $\mathrm{X}$ :

$$
I(X ; Y)=H(X)-H(X \mid Y)
$$

Reducing the amount of available information entropy to measure the impact on the query node evidence nodes, and in accordance with the effects of size on the evidence of that sort, sensitivity analysis.

Households' demand for agricultural technology is the result of internal and external causes. There are many factors to influence agricultural technology demand of farmers, whether it is hindering force or driving force. The farmer's own characteristics, composition of income, the land area of 
family, sources of technical information will have different influence on, the specific variables see table 1.

Table 1 Related to variable definitions and units

\begin{tabular}{|c|c|}
\hline Correlation variable & Efinition of variables and their units \\
\hline (householder) & \\
\hline characteristics & $20-30,30-40,40-50,50-60$, above 60 years old \\
\hline 1.Age & mail,femail \\
\hline 2.sex & college degree or above, high school, junior high school, primary \\
\hline 3.educational status & school, illiterate \\
\hline 4 hoalth ctatuc & healthy,unhealthy \\
\hline 5 residential areas & rural, suburban \\
\hline 6.migrant workers & yes,no \\
\hline experience & \\
\hline 7.communist & ves,no \\
\hline 8.cardres & yes, 110 \\
\hline $\begin{array}{l}\text { omposition of income } \\
\text { 1.per capita annual family }\end{array}$ & $\begin{array}{l}\text { Yuan(below } ¥ 3000, ¥ 3000-4000, ¥ 4000-5000 \text {, } ¥ 5000 \text {-6000, more } \\
\text { than } ¥ 6000 \text { ) }\end{array}$ \\
\hline $\begin{array}{l}\text { income } \\
\text { 2.proportion of }\end{array}$ & $\%$ (below 10\%,10-20\%,20-30\%,over 30\%) \\
\hline $\begin{array}{l}\text { non-agricultural income } \\
\text { 3.acreage }\end{array}$ & Mu(below $10 \mathrm{mu}, 10-20 \mathrm{mu}, 20-30 \mathrm{mu}$, more than $30 \mathrm{mu}$ ) \\
\hline $\begin{array}{l}\text { Sources of technical } \\
\text { information }\end{array}$ & \\
\hline 1.technical guidance & yes,no \\
\hline 2.technology demonstration & yes,no \\
\hline 3.training or seminars & yes,no \\
\hline 4.farmer cooperative & yes,no \\
\hline $\begin{array}{l}\text { organization } \\
\text { preferred technology }\end{array}$ & $\begin{array}{l}\text { fertilization technology, pest control technology, } \\
\text { storing-processing technology, farming implements use } \\
\text { technology, film technology, breeding technology, chemical } \\
\text { weeding technology and other technology }\end{array}$ \\
\hline
\end{tabular}

This paper wants to analyze the farmers' technical demand by the use of Bayesian network, in order that we can find the main influence factors. Through a variety of methods to improve intention and skills of adopting new technology.

\section{Organization of the Text}

In order to solve this problem, we choosed eight cities and counties from Jilin Province, Nong'an, Yushu, Yongji, Qianguo, Ningjiang, Meihekou, Lishu, to investigate farmers preferred technical demand. The preferred technology including fertilization technology, pest control technology, storing-processing technology, farming implements use technology, film technology, breeding technology, chemical weeding technology and other technology, etc. Survey a total of 1600 samples, after rejecting invalid data, eventually formed contains 1461 valid samples.

Model and analysis of results in this paper, using the Bayesian network software (developed by the American Norsys company Netica software), according to the data in the table to obtain the Bayesian network in the form of, see figure1. 
Sensitivity analysis of the network, the information entropy is bigger, sensitivity is higher. In many elements, the information entropy of age is the most, so sensitivity is the highest, impact is the greatest; the information entropy of whether communist and cadres or not is the minimum, so sensitivity is the lowest, effect is the lowest, see table 2.

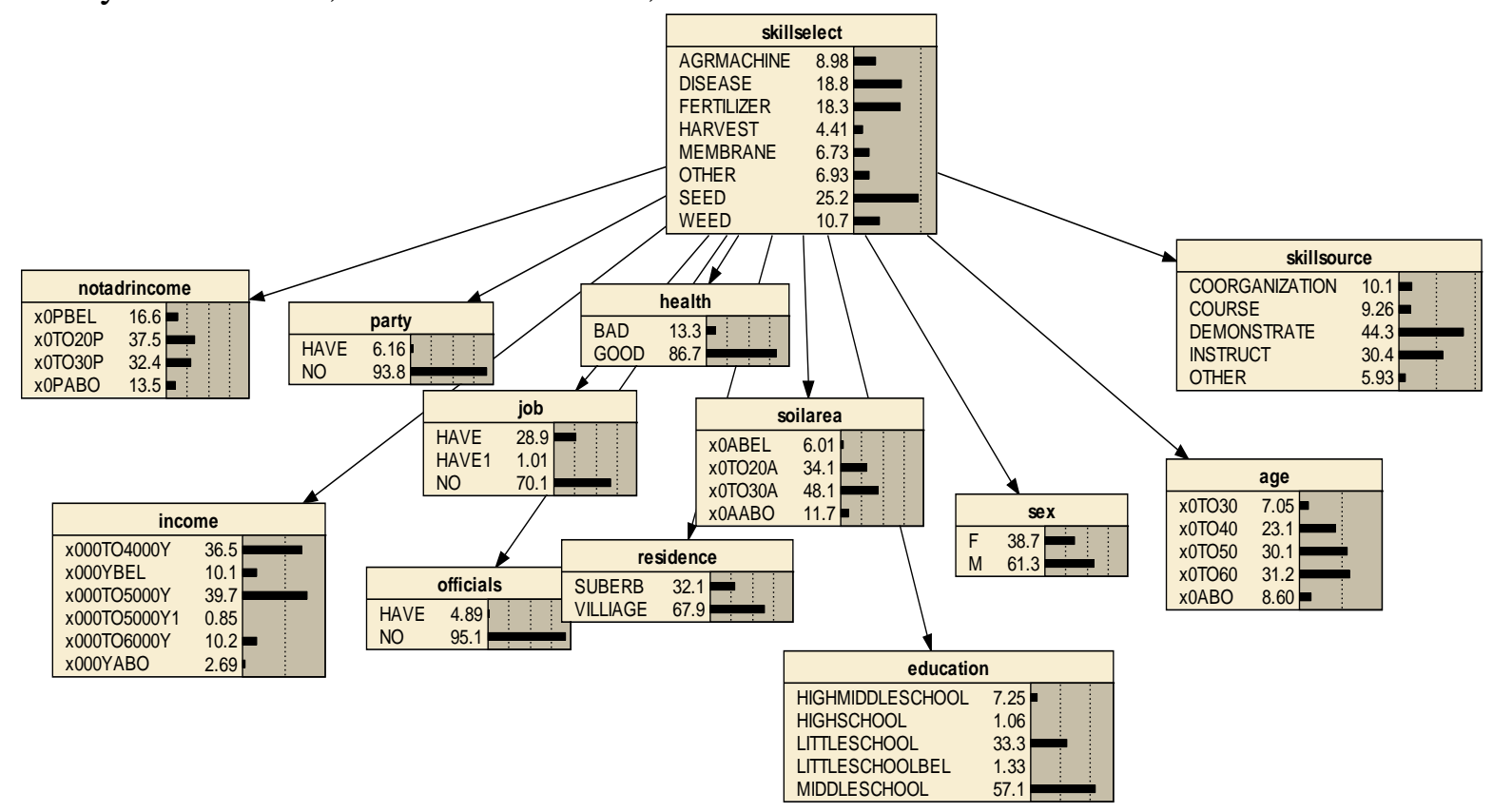

Figure 1 The Bayesian network of farmers preferred technology factors

Table2 Sensitivity analysis for farmers preferred technology

\begin{tabular}{ccc}
\hline The effect of attribute & Imformation entropy & $\%$ \\
\hline age & 0.26902 & 23.00 \\
per capita nanual family income & 0.18929 & 16.18 \\
the proportion of non-agricultural income & 0.11966 & 10.23 \\
acreage & 0.10655 & 9.11 \\
rdsidential area & 0.09942 & 8.50 \\
sources of technical information & 0.09466 & 8.09 \\
migrant workers experience & 0.08855 & 7.57 \\
sex & 0.06685 & 5.72 \\
educational status & 0.05474 & 4.68 \\
health status & 0.04591 & 3.93 \\
\hline
\end{tabular}

For the single a technology, Bayesian network, reduce the amount and the sensitivity analysis by means of entropy, so as to determine the effect order of technology adoption factors. From the order, we obtain the following conclusions:

(1) Preferred techniques ranking as: breeding technology, pest control, fertilization technology, chemical weeding techniques, farming implements use technology, other technology, film technology, storing-processing technology. To produce this conclusion may be because the most farmers in Jilin province are in engaged in traditional agricultural production activity, thus the breeding technology, pest control, fertilization technology and chemical weeding technology are needed more.

(2) influence factors ranking as: age, family per capita income, non-agricultural income, acreage, living area, sources of technical information, migrant workers experience, sex, educational status, health status, communist and cadre or not. Factors affecting the choice of comprehensive sequencing technology, we can see that age, family per capita income, non-agricultural income and land management area are is the most obvious factors that influence farmers to accept technology. 
(3) The influence factor to a single preferred technology is slightly different. To the fertilization technology, the sources of technical information is the most influence factor; to the pest control technology, chemical weeding technology, film technology and other technology, age is the most important influence factor; to breeding technology, farming implements use technology, storingprocessing technology, family per capita income is the most important influence factor.

Take fertilization technology, we analyze the entropy reduction and sensitivity to a single preferred technology. The information entropy is bigger, sensitivity is higher. Among many factors, the technology source is the largest information entropy to fertilization, so the highest sensitivity. The top three influence factors of the preferred technology of fertilization are sources of technical information, age and family per capita income, see table 3.

Table3 The order of farmers preferred fertilization factors

\begin{tabular}{ccc}
\hline The effect of attribute & Information entropy & $\%$ \\
\hline sources of technical information & 0.04202 & 26.92 \\
age & 0.03932 & 25.19 \\
per capita annual family income & 0.02618 & 16.77 \\
migrant workers experience & 0.02027 & 12.99 \\
educational status & 0.00877 & 5.62 \\
the proportion of non-agricultural income & 0.00859 & 5.50 \\
health status & 0.00409 & 2.62 \\
\hline
\end{tabular}

\section{Summary}

According to the Bayesian network method, the important factors to influence farmers preferred technique are the age, family income and land management area. Therefore, the agricultural technology extension to take into account the differences in age, income and technology receivers operating land area, according to the farmers' individual differences and the actual needs to be targeted to the popularization of agricultural technology.

\section{Reference}

[1] Yu Helong,Chen Guifen,Dong Xuchu. Development and application of expert system platform based on Bayesian network[J]. Natural Science Journal of Heilongjiang University, 2008(8):492-497. 